\title{
ASSOCIATION BETWEEN OBESITY AND DEPRESSION IN MIDDLE-AGED WOMEN
}

\author{
Gregory E Simon, MD MPH ${ }^{1}$, Evette J Ludman, $\mathrm{PhD}^{1}$, Jennifer A Linde, $\mathrm{PhD}^{2}$, Belinda H \\ Operskalski, MPH ${ }^{1}$, Laura Ichikawa, $\mathbf{M S}^{1}$, Paul Rohde, PhD $^{3}$, Emily A Finch, MA $^{2}$, and Robert \\ W Jeffery, $\mathbf{P h D}^{2}$ \\ 1 Center for Health Studies, Group Health Cooperative, Seattle, WA \\ 2Division of Epidemiology and Community Health, School of Public Health, Univ. of Minnesota, Minneapolis \\ 3Oregon Research Institute, Eugene
}

\section{Abstract}

Objective-Evaluate the association between obesity and depression among middle-aged women.

Methods-4641 female health plan enrollees aged 40-65 completed a structured telephone interview including self-reported height and weight, the Patient Health Questionnaire (PHQ) assessment of depression, a brief measure of rate was $62 \%$.

\begin{abstract}
Results-Prevalence of moderate or severe depression increased from $6.5 \%$ among those with body mass index (BMI) under 25 to $25.9 \%$ among those with BMI over 35. Prevalence of obesity increased from $25.4 \%$ among those with no depressive symptoms to $57.8 \%$ among those with moderate to severe depression. Independent of obesity, depression was associated with significant reductions in frequency of moderate (4.6 vs. 5.4 times per week) or vigorous ( 2.8 vs. 3.7 times per week) physical activity. Depression was associated with significantly higher daily caloric intake (1831 vs. 1543) among those with BMI over 30 .
\end{abstract}

Conclusions-Among middle-aged women, depression is strongly and consistently associated with obesity, lower physical activity, and (among the obese) higher caloric intake. Public health approaches to reducing the burden of obesity or depression must consider the strong association between these two common conditions.

Obesity is a major public health concern. Among US adults, prevalence of obesity (defined as a Body Mass Index or BMI of 30 or more) increased from approximately 23\% in 1990 to 31\% in $2000^{1}$. Similar increases were seen for men and women, across all age groups, and across all racial/ethnic groups. ${ }^{12}$ More recent data indicate no improvement in this trend between 2000 and $2002^{2}$. Adverse consequences of obesity, such as diabetes and cardiovascular disease, are predicted to cause an unprecedented decline in life expectancy in the United States ${ }^{3}$.

Beginning in the 1970s, numerous epidemiologic studies have examined the association between obesity and depression or other psychiatric disorders. Early research in the UK 45 suggested a negative association between obesity and symptoms of depression or anxiety. Subsequent studies had variable results, with some ${ }^{67}$ finding no significant association

\footnotetext{
Author address: Gregory Simon Center for Health Studies 1730 Minor Ave. Seattle, WA 98101 Phone: 206-287-2979 Fax: 206-287-2871. Publisher's Disclaimer: This is a PDF file of an unedited manuscript that has been accepted for publication. As a service to our customers we are providing this early version of the manuscript. The manuscript will undergo copyediting, typesetting, and review of the resulting proof before it is published in its final citable form. Please note that during the production process errors may be discovered which could affect the content, and all legal disclaimers that apply to the journal pertain.
} 
between obesity and depression, some finding a positive association limited to women 8-12 finding stronger associations in women than men, and some 111314 finding associations limited to severe obesity. While the majority of recent US and Canadian studies 1114-17 suggest a moderate association between obesity and depression, some studies in Europe and Asia find no association 18 or an inverse relationship 1920 .

Methodologic differences may account for some of the variability in previous research regarding obesity and depression. Previous studies have used varying measures of depression, including depression screening questions ${ }^{12}$, symptom scales 8916 , and structured diagnostic interviews $10-12$. The relationship between obesity and depression may be either confounded or moderated by sociodemographic characteristics such as race or socioeconomic status 12 21 . Most previous studies have not examined potential mechanisms or mediators of this relationship, such as body dissatisfaction or differences in caloric intake and physical activity.

The present paper uses data from a large sample of middle-aged women enrolled in a prepaid health plan to: 1) Assess the association between various levels of obesity and various levels of depression severity; 2) Examine potential confounders of the association including tobacco use and use of antidepressant medications; 3) Evaluate how the association between obesity and depression varies as a function of age, race, marital status, and educational attainment; and 4) Examine differences in body satisfaction, dietary intake and physical activity level that might help to explain any association.

\section{METHODS}

Data used in this paper were obtained through a population-based survey of middle-aged women enrolled in Group Health Cooperative, a group-model prepaid health plan serving approximately 500,000 members in Washington and northern Idaho. Most Group Health members are enrolled via employer-purchased contracts, but approximately 20,000 are enrolled via risk-sharing contracts with Medicare and another 20,000 via risk-sharing contracts with Medicaid or other subsidized low-income programs. The Group Health enrollment is demographically similar to the area population ${ }^{22}$. Study participants were recruited from eight Group Health primary care clinics selected for higher rates of minority enrollment. All study procedures were approved by the Group Health Institutional Review Board.

All women aged 40 and older enrolled in Group Health are invited to complete periodic breast cancer risk questionnaires including self-reported height and weight ${ }^{23}$. In order to over-sample women expected to have higher BMI, data from this breast cancer screening program were used to stratify the population of women aged 40 to 65 into three groups. Women who last reported a BMI of 30 or more were sampled at $100 \%$, women who last reported a BMI less than 30 were sampled at $12 \%$, and women who did not complete a screening questionnaire in the last five years were sampled at $25 \%$. This stratified sampling procedure was intended to increase the efficiency of the survey and to permit correction for differences in response rates. All analyses incorporated sampling weights (see below) so that results accurately reflect the entire population of women aged 40 to 65 .

All sampled participants were mailed an invitation letter including core elements of informed consent (purpose of the study, study procedures, risks, voluntary nature of participation, procedures to protect confidentiality). The letter included a $\$ 5$ gift card incentive and a phone number through which potential participants could decline further contact. Those who did not decline were contacted by telephone beginning approximately one week after mailing of the invitation letter. Participants received no additional compensation for completing the survey. 
Surveys were conducted by trained interviewers from Group Health's survey research program. Each interviewer received at least 8 hours of general interview training and 4 hours of projectspecific training. Certification required satisfactory performance in 2 role-play interviews and 2 observed interviews. Contact protocols required a minimum of 9 contact attempts, including attempts during evening and weekend times.

Each survey began with a detailed consent script repeating all elements of informed consent, and each participant provided documented oral consent prior to participation.

The telephone survey included the following measures:

- Self-reported height, weight, race/ethnicity, marital status, current and past tobacco use, and educational attainment.

- The 9-item Patient Health Questionnaire or PHQ - This self-report measure of depression symptoms examines the nine American Psychiatric Association DSM-IV 24 criteria for diagnosis of major depressive episode. Validation studies in the general population 25 as well as in general medical outpatients 2627 and medical inpatients 28 have shown excellent agreement between the self-report PHQ and a clinician structured interview. To assess diagnosis of current major depression, each item was scored as positive if endorsed as "More than half the time" or "Nearly all the time". A diagnosis of major depression required a positive response to one of the two core symptoms (depressed mood or loss of interest) and a total of five positive symptoms. In addition, a dimensional score was calculated as the total of all 9 items (possible range 0 to 27). A score of 10 or more on this scale represents a moderate level of depressive symptoms 27 .

- A 13-item measure of physical activity developed by Jacobs 29 assessing frequency (number of times each week) that respondents typically engaged in specific moderate physical activities (e.g. walking, bowling, household work) or vigorous physical activities (e.g. jogging, lap swimming, aerobic exercise classes) over the last year.

- An abbreviated 12-month food frequency questionnaire based on the questionnaire originally developed by Block for the National Cancer Institute ${ }^{3031}$. The abbreviated questionnaire included 39 items found to account for over $90 \%$ of the variance in estimated caloric intake measured by the full questionnaire ${ }^{32}$. The full questionnaire and the abbreviated version would both be expected to underestimate actual caloric intake, but both should accurately assess group differences in intake.

- Body dissatisfaction was assessed using a single item ("I feel satisfied with the shape of my body") with responses ranging from 0 ("Always") to 5 ("Never").

A sample of 250 women reporting BMI of 30 or more were invited to in in-person assessment to assess eligibility for a treatment study. At this assessment, height was measured by stadiometer and weight was measured by triple-beam balance. Comparison of self-reported height and weight with directly measured height and weight found that weight was underreported by an average of $1.35 \mathrm{~kg}$ and height was under-reported by an average of .002 meters. In this validation subsample, Pearson's correlations between measured and self-reported heights and weights were $r=0.95$ and $r=0.98$, respectively 33 .

All analyses incorporate sampling weights 34 to account for the stratified sampling procedure described above and for differential response rates across sampling strata (see below). All data analyses were conducted using SAS/STAT® software, Version 9.1. The Taylor series expansion approximation was used to adjust confidence intervals and significance tests for design effects (potential over-estimation of statistical significance due to the stratified sampling design). Specific SAS procedures used included SURVEYFREQ for calculation of 
proportions, SURVEYREG for linear regression models, and SURVEYLOGISTIC for logistic regression models.

\section{RESULTS}

Of 8000 potential participants who were mailed invitation letters, 442 were found to be ineligible (had since died, moved away, or disenrolled from the health plan). Of the remaining 7558 eligible women, 865 could not be reached by telephone and 2033 declined to participate, leaving 4660 participants (62\% of those eligible). Nineteen participants had missing data on one or more key variables, so 4641 were included in analyses presented here. Participation varied significantly across sampling strata (63\% among those who reported BMI of 30 or more on the breast cancer screening questionnaire vs. 59\% among those reporting BMI less than 30 vs. $34 \%$ among those declining to participate in breast cancer screening, $X^{2}=344, \mathrm{df}=2, \mathrm{p}<$. 001). As discussed above, all analyses incorporated sampling weights to correct for differential response across strata.

Weighted prevalence of current major depressive episode by strict diagnostic criteria was $5.1 \%$, and an additional $7.7 \%$ had PHQ scores of 10 or greater (a conventional threshold for moderate symptoms of depression). Weighted prevalence of obesity was $33.4 \%$, with $17.7 \%$ having BMI between 30 and 35 and an additional 15.7\% having BMI of 35 or greater (the customary threshold for severe or morbid obesity. These rates are consistent with expectations for prevalence of depression 35 and obesity 2 in a sample of middle-aged women.

Figure 1 displays the prevalence of depression according to BMI. Whether depression was defined by current major depressive episode or by PHQ score of 10 or more, prevalence of depression was progressively higher as BMI increased from normal to morbidly obese. Compared to those with BMI less than 25, the relative odds of having a PHQ score of 10 or more were 3.83 (95\% CI 1.89 to 7.76) for those with BMI between 25 and 30, 4.40 (95\% CI 2.21 to 8.78 ) for those with BMI between 30 and 35, and 4.95 (95\% CI 3.47 to 7.05 ) for those with BMI of 35 or more. Compared to those with BMI less than 25, relative odds of satisfying criteria for current major depressive episode were 1.92 (95\% CI 1.26 to 2.92) for those with BMI between 25 and 30, 2.92 (95\% CI 1.98 to 4.29) for those with BMI between 30 and 35, and 5.72 (95\% CI 3.02 to 10.85) for those with BMI of 35 or more. Figure 2 displays prevalence of obesity according to depression status. Compared to those with PHQ score less than 5, relative odds of obesity were 2.26 (95\% CI 1.86 to 2.73) for those with PHQ score of 5 to 9 , 3.38 (95\% CI 2.50 to 4.57 ) for those with PHQ score of 10 to 15 , and 4.02 (95\% CI 2.63 to 6.15) for those with PHQ score of 15 or more. All subsequent analyses considered dichotomous measures of obesity (BMI less than 30 vs. 30 or more) and depression (PHQ score less than 10 vs. 10 or more). Using these dichotomous thresholds yielded an odds ratio of 2.82 (95\% CI 2.20 to 3.62) for the association between obesity and depression.

Diagnostic criteria for depression such as fatigue or appetite change could be confounded with physical effects of obesity. Consequently, additional analyses examined the association between obesity and specific depression criteria less likely to be directly determined by physical consequences of obesity. Using a threshold of BMI greater than or equal to 30, odds ratios for association between obesity and individual depression criteria were 1.94 (95\% CI 1.42 to 2.66) for depressed mood, 2.39 (95\% CI 1.81 to 3.17) for loss of interest in activities, 2.65 (95\% CI 1.96 to 3.57) for feelings of guilt or worthlessness, and 1.48 (95\% CI 0.68 to 3.68) for suicidal ideation.

The top portion of Table 1 compares demographic characteristics, tobacco use, and antidepressant use for groups defined by both obesity and depression status. Obesity was associated with African American race, single marital status, lower educational attainment and 
more frequent use of antidepressant medication. Depression was associated with single marital status, lower educational attainment, higher rates of current tobacco use, and more frequent use of antidepressant medication. Adjustment for age and race had no meaningful effect on the association between obesity and depression (adjusted odds ratio $=2.84,95 \%$ CI 2.21 to 3.65). Further adjustment for educational attainment, marital status, smoking status, and antidepressant use yielded an odds ratio of 2.37 (95\% CI 1.81 to 3.10).

Additional analyses examined whether the association between depression and obesity varied according to age, race, marital status, and educational attainment. We observed no statistically significant interaction across any of those demographic classifications ( $\mathrm{p} \geq .23$ for all comparisons).

The bottom portion of Table 1 compares self-reported physical activity, estimated caloric intake, and body dissatisfaction for groups defined by both obesity and depression status. Highest levels of physical activity by both measures were seen in those who were neither obese nor depressed, and lowest levels were seen among those who were both obese and depressed. Table 2 displays the independent effects of both obesity and depression on measures of physical activity. After accounting for the effect of obesity, depression was associated with significant reductions in frequency of moderate and vigorous physical activity. For both types of exercise, the adjusted differences associated with depression was approximately half as large as the adjusted differences associated with obesity. The pattern was similar for body dissatisfaction: lowest scores in those who were neither obese nor depressed and highest (most dissatisfied) scores in those who were both obese and depressed. As shown in the bottom of Table 2, depression was independently associated with body dissatisfaction after accounting for the association with obesity. The magnitude of the association between body dissatisfaction and depression was approximately half as large as that between body dissatisfaction and obesity.

As shown in the bottom row of Table 1, the relationship between depression and caloric intake appeared to differ between obese and non-obese respondents. Among the non-obese, depression was not associated with higher caloric intake. Among the obese, depression was associated with nearly $20 \%$ higher caloric intake. This appearance of effect modification was confirmed by a linear regression model predicting caloric intake as a function of obesity, depression, and the interaction of the two ( $\mathrm{p}<0.001)$. Subgroup analyses found no significant association between caloric intake and depression in those with BMI less than $30(\mathrm{p}=.59)$ and a highly significant relationship in those with BMI of 30 or more $(\mathrm{p}<.001)$.

\section{DISCUSSION}

In this sample of middle-aged women, we observe a strong and consistent relationship between obesity and depression. Prevalence of depression (whether defined by diagnostic criteria or severity of symptoms) was more than twice as great among women with BMI of 30 or more compared to those with BMI less than 30 , and this strong association was seen across different age groups, racial and ethnic groups, and levels of educational attainment. Furthermore, we observed a step-wise increase in both directions: increasing severity of depressive symptoms was strongly associated with higher risk of obesity, and increasing body mass index was strongly associated with higher risk of depressive disorder. We do not find that the association between obesity and depression was limited to more severe obesity. This association was only minimally affected by accounting for potential confounders such as educational attainment, marital status, tobacco use, and antidepressant drug use. The association could not be attributed to selective effects of obesity on somatic symptoms of depression.

The association between obesity and depression in this sample is considerably stronger than that seen in previous US ${ }^{10-12}$ and Canadian ${ }^{16}$ surveys where odds ratios ranged from 
approximately 1.4 to 1.8 among women. We must consider whether any differences in study design or method might account for the much stronger association seen in this sample.

First, our survey may have focused on the demographic groups in which the obesity-depression association is strongest. While we did not find that the association between obesity and depression varied across demographic groups, previous research suggests that this relationship may vary by age, socioeconomic status, or ethnicity. Community survey data from the 1950s suggest a stronger association between obesity and depression among those with higher socioeconomic status ${ }^{21}$. A more recent US survey ${ }^{12}$ found a stronger association in those under age 65 compared to older respondents. In another US population survey ${ }^{12}$, depression and obesity were more strongly associated in non-Hispanic whites and those with higher educational attainment. International studies 1920 suggest that the association observed in predominantly Caucasian samples in the US and Canada may not extend to other racial or ethnic groups. Our sample was relatively homogeneous, and it may have included primarily those for whom the relationship between obesity and depression appears to be the strongest: middle-aged women who were predominantly middle-class and Caucasian.

Second, only $62 \%$ of those potentially eligible participated in the survey. Our results might over-estimate the association between obesity and depression if women with both conditions were more likely to participate than those with either alone. We did observe a slightly higher response rate among those who previously reported a higher BMI, but all analyses were weighted to correct for this potential bias.

Third, depression was assessed by non-clinicians using a structured research interview rather than by a full clinical assessment. Inaccurate measurement of depression, however, would generally lead to a conservative bias (underestimating the association between depression and obesity). We would not expect an imperfect measure of depression to differentially overestimate depression in those with higher body mass index. Compared to the gold standard of a clinician assessment, the validity of the PHQ 2627 is as good or better than alternative measures used in previous studies $8-1116$. In addition, our finding of a strong association between depression and obesity did not depend on whether the PHQ was analyzed as a diagnostic assessment or a measure of symptom severity.

Fourth, height and weight were assessed by self-report. Previous methodologic research suggests that self-reported height and weight are highly correlated with direct physical measurements $36-38$, but self-report tends to consistently under-estimate weight and overestimate height ${ }^{37}$. In a sample of participants in this study, weight was under-reported by less than $1.5 \mathrm{~kg}$ on average, and correlation between self-reported and measured weight was 0.98 *. In addition, we would not expect that a general tendency to under-report weight would affect the association between obesity and depression. Previous studies demonstrating an association between obesity and depression have included both self-report 1012 and physical measurements 91116 of height and weight.

Fifth, our analyses do not consider the possible influence of previous depressive episodes on weight, physical activity, or diet. Over $20 \%$ of women with $\mathrm{BMI} \geq 30$ and $\mathrm{PHQ}<10$ reported current or recent use of antidepressants, suggesting a significant rate of prior depression. Misclassification of depression, however, would be expected to blunt or obscure the association between depression and obesity.

Sixth, some physical or somatic criteria for diagnosis of depression, such as fatigue or disturbances in appetite, could be confounded with manifestations of obesity. We find, however, that obesity is strongly related to psychological symptoms such as depressed mood, feelings of guilt, or suicidal ideation. A similar concern has been raised regarding biased 
assessment of depression in chronic medical illness ${ }^{3940}$. Psychometric analyses, however, have not found evidence for such bias 41 .

Previous research suggests several mechanisms for an association between obesity and depression. Various potential mechanisms have been described ${ }^{42-44}$. Some mechanisms propose that depression causes or contributes to obesity. Common symptoms of depression include increased appetite 4546 and reduced physical activity ${ }^{47}$. Reduced motivation or selfefficacy associated with depression may interfere with initiating or maintaining exercise programs or diet change. Depression may increase risk of weight gain through its effect on binge eating 4849 , especially among women 5051 . Medications used to manage mood or anxiety disorders may also lead to weight gain 52 . Alternatively, some proposed mechanisms suggest that obesity causes or contributes to depression. The stigma attached to obesity (especially for women) may contribute to depression ${ }^{53}$, and this stigma may vary by race/ ethnicity or socioeconomic status ${ }^{54-57}$. Activity limitations or due to obesity or obesityrelated chronic illnesses may increase risk of depression through distressing physical symptoms or decreased involvement in rewarding or pleasurable activities ${ }^{15}$. Finally, depression and obesity may be linked through some common cause or third factor, either environmental (e.g. childhood abuse ${ }^{58}$ ) or biological.

We examine three potential mediators of the relationship between obesity and depression: physical activity, caloric intake, and body satisfaction.

In this sample, depression was independently associated with decreased physical activity after accounting for the association between physical activity and obesity. This observation is, of course, consistent with causal mechanisms in either direction: depression causing obesity or obesity causing depression. In the former scenario, depression may lead do decreased physical activity and subsequently to weight gain. In the latter scenario, decreased physical activity associated with obesity might contribute to depressed mood. In either case, however, our data suggest that physical activity level is a potential mediator of this relationship.

Depression was strongly associated with increased caloric intake among the obese, but we observed no association among those with BMI less than 30 . This may reflect population subgroups experiencing different effects of depression on appetite or weight. Depression may be associated with either increased or decreased appetite. Increased appetite associated with depression tends to be consistent across episodes 4546 (although this is not a universal finding 59 ). Again, our findings suggest that increased caloric intake is a potential mediator of the relationship between obesity and depression.

Body dissatisfaction was also associated with depression after accounting for the relationship between body satisfaction and BMI. This finding is consistent with the hypothesis that obesity contributes to depression by way of stigmatization and reduced self-esteem ${ }^{13}$.

This cross-sectional study cannot, of course, clearly establish either the direction of the causal relationship between obesity and depression or the mechanism of that relationship. Our findings do, however, suggest that the relationship probably involves multiple mechanisms including decreased physical activity, increased caloric intake, and negative body image.

To illustrate the public health importance of the relationship between obesity and depression, we can examine the population attributable fraction, the proportion of any disease attributable to its association with a particular risk factor. By this measure, we estimate that $33 \%$ of the risk of depression in this population could be attributable to its association with obesity or that 9\% of the risk of obesity could be attributable to its association with depression. These calculations do not, of course, demonstrate a causal relationship. They simply illustrate the significance of a strong association between two common health conditions. As alternative 
indicators of public health importance, we point out the extremely high rates of comorbidity at the extremes of depression and obesity. Those with BMI of 35 or more (a conventional threshold for morbid obesity) had a $26 \%$ prevalence of clinically significant depressive symptoms. Those with PHQ scores of 15 or more (indicating more severe depression) had a $58 \%$ prevalence of obesity.

\section{CONCLUSIONS}

Among middle-aged women, obesity is strongly associated with depression. This association is consistent across demographic groups and is not explained by confounding effects of age, race, marital status, educational attainment, tobacco use, or antidepressant use. Depression is associated with significantly lower physical activity levels and, among the obese, higher caloric intake. Public health approaches to reducing the burden of obesity or depression must consider the strong association between these two common conditions.

\section{ACKNOWLEDGEMENTS}

Supported by NIMH grant R01 MH068127. The funder had no role in design and conduct of the study; collection, management, analysis, and interpretation of the data; and preparation, review, or approval of the manuscript. Dr. Simon had full access to all the data in the study and takes responsibility for the integrity of the data and the accuracy of the data analysis.

\section{Reference List}

1. Flegal K, Carroll M, Ogden C, Johnson C. Prevalence and trends in obesity among US adults, 1999-2000. JAMA 2002;288:1723-7. [PubMed: 12365955]

2. Hedley A, Ogden C, Johnson C, Carroll M, Curtin L, Flegal K. Prevalence of overweight and obesity among US children, adolescents, and adults, 1999-2002. JAMA 2004;291:2847-50. [PubMed: 15199035]

3. Olshansky S, Passaro D, Hershow R, et al. A potential decline in life expectancy in the United States in the 21st century. NEJM 2005;352:1138-45. [PubMed: 15784668]

4. Crisp A, McGuiness B. Jolly fat: relation between obesity and psychoneurosis in general population. Br Med J 1976;1(6000):7-9. [PubMed: 1247732]

5. Crisp A, Queenan M, Sittampaln Y, Harris G. 'Jolly fat' revisited. J Psychsom Res 1980;24:233-41.

6. Hallstrom T, Noppa H. Obesity in women in relation to mental illness, social factors, and personality traits. J Psychosom Res 1981;25:75-82. [PubMed: 7277275]

7. Faubel M. Body image and depression in women with early and late onset obesity. J Psychology 1989;123:385-95.

8. Palinkas L, Wingard D, Barrett-Connor E. Depressive symptoms in overweight and obese older adults: a test of the "jolly fat" hypothesis. J Psychosom Res 1996;40:59-66. [PubMed: 8730645]

9. Istvan J, Zavela K, Weidner G. Body weight and psychological distress in NHANES I. Int J Obes Relat Metab Disord 1992;16:999-1003. [PubMed: 1335980]

10. Carpenter K, Hasin D, Allison D, Faith M. Relationships between obesity and DSM-IV major depressive disorder, suicide ideation, and suicide attempts: Results from a general population study. Am J Public Health 2000;90:251-7. [PubMed: 10667187]

11. Onyike C, Crum R, Lee H, Lyketsos C, Eaton W. Is obesity associated with major depression? Results from the Third National Health and Nutrition Examination Survey. Am J Epidemiol 2003;158:113947. [PubMed: 14652298]

12. Heo M, Pietrobelli A, Fontaine K, Sirey J, Faity M. Depressive mood and obesity in US adults: comparision and moderation by sex, age, and race. Into J Obes. 2005epub Nov 15

13. Friedman K, Reichmann S, Costanzo P, Musante G. Body image partially mediates the relationship between obesity and psychological distress. Obes Res 2002;10:33-41. [PubMed: 11786599]

14. Dong C, Sanchez L, Price R. Relationship of obesity to depression: a family-based study. Int J Obes Relat Metab Disord 2004;28:790-5. [PubMed: 15024401] 
15. Roberts R, Strawbridge W, Deleger S, Kaplan G. Are the fat more jolly. Ann Behav Med 2002;24:16980. [PubMed: 12173674]

16. Johnston E, Johnston S, McLeod P, Johnston M. The relation of body mass index to depressive symptoms. Can J Public Health 2004;95:179-83. [PubMed: 15191118]

17. Simon G, VonKorff M, Saunders K, et al. Association between obesity and psychiatric disorders in the US adult population. Arch Gen Psychiatry 2006;63:824-30. [PubMed: 16818872]

18. John U, Meyer C, Rumpf H, Hapke U. Relationships of psychiatric disorders with overweight and obesity in an adult general population. Obes Res 2005;13:101-9. [PubMed: 15761168]

19. Jasienska G, Ziomkiewicz A, Gorkiewicz M, Pajak A. Body mass, depressive symptoms, and menopausal status: an examination of the "Jolly Fat" hypothesis. Womens Health Issues 2005;15:145-51. [PubMed: 15894200]

20. Bin Li Z, Yin Ho S, Man Chan W, et al. Obesity and depressive symptoms in Chinese elderly. Int J Geriatr Psychiatry 2004;19:68-74. [PubMed: 14716701]

21. Moore M, Stunkard A, Srole L. Obesity, social class, and mental illness. JAMA 1962;181:962-6. [PubMed: 14475695]

22. Simon G, VonKorff M, Barlow W, Pabiniak C, Wagner E. Predictors of chronic benzodiazepine use in a health maintenance organization sample. J Clin Epidemiol 1996;49:1067-73. [PubMed: 8780618]

23. Taplin S, Thompson R, Schintzer F, Anderman C, Immanuel V. Revisions in the risk-based Breast Cancer Screening Program at Group Health Cooperative. Cancer 1990;66:812-8. [PubMed: 2386908]

24. American Psychiatric Association. Diagnostic and Statistical Manual of Mental Disorders. Vol. Fourth Edition. American Psychiatric Association; Washington, DC: 1994.

25. Martin A, Rief W, Klaiberg A, Braehler E. Validity of the Brief Patient Health Questionnaire Mood Scale (PHQ-9) in the general populatoin. Gen Hosp Psychiatry 2006;28:71-7. [PubMed: 16377369]

26. Spitzer R, Kroenke K, Williams J. Validation and utility of a self-report version of PRIME-MD: the PHQ primary care study. JAMA 1999;282:1737-44. [PubMed: 10568646]

27. Kroenke K, Spitzer R, Williams J. The PHQ-9: Validity of a brief depression severity measure. J Gen Intern Med 2001;16:606-13. [PubMed: 11556941]

28. Diez-Quevedo C, Rangil T, Sanchez-Planell L, Kroenke K, Spitzer R. Validation and utility of the patient health questionnaire in diagnosing mental disorders in 1003 general hospital Spanish inpatients. Psychosom Med 2001;63:679-86. [PubMed: 11485122]

29. Jacobs D, Hahn L, Haskell W, Pirie P, Sidney S. Validity and reliability of short physical activity history: Cardia and the Minnesota Heart Health Program. J Cardiopulmonary Rehabil 1989;9:44859.

30. Block G, Hartman A, Dresser C, Carroll M, Gannon J, Gardner L. A data-based approach to diet questionnaire design and testing. Am J Epidemiol 1986;124:453-69. [PubMed: 3740045]

31. Block G, Woods M, Potosky A, Clifford C. Validation of a self-administered diet history questionnaire using multiple diet records. J Clin Epidemiol 1990;43:1327-35. [PubMed: 2254769]

32. Linde J, Jeffery R, Baxter J, Wing R. A brief self-report method to assess total energy intake. 12th Annual Meeting of the North American Association for the Study of Obesity.

33. Jeffery R, Finch E, Linde J, et al. Does clinical depression affect the accuracy of self-reported height and weight in obese women? Obes Res. in press

34. Cochran, W. Sampling techniques. Wiley; New York: 1977.

35. Kessler R, Berglund P, Demler O, et al. The epidemiology of major depressive disorder: results from the National Comorbidity Survey Replication. JAMA 2003;289:3095-105. [PubMed: 12813115]

36. Stevens J, Keil J, Waid L, Gazes P. Accuracy of current, 4-year, and 28-year self-reported body weight in an elderly population. Am J Epidemiol 1990;132:1156-63. [PubMed: 2260547]

37. Kuczmarski M, Kuczmarski R, Najjar M. Effect of age on validity of self-reported height, weight, and body mass index: findings from the Third National Health and Nutrition Examination Survey, 1988-1994. J Am Diet Assoc 2001;101:28-34. [PubMed: 11209581] 
38. Niedhammer I, Bugel I, Bonenfant S, Goldberg M, Leclerc A. Validity of self-reported weight and height in the French GAZE cohort. Int J Obes Relat Metab Disord 2000;24:1111-8. [PubMed: 11033979]

39. Koenig H, George L, Peterson B, Pieper C. Depression in medically ill hospitalized older adults: Prevalence, characteristics, and course of symptoms according ot six diagnostic schemes. Am J Psychiatry 1997;154:1376-83. [PubMed: 9326819]

40. von Amman Cavanaugh S. Depression in the medically ill. Critical issues in diagnostic assessment. Psychosomatics 1995;36:48-59. [PubMed: 7871134]

41. Simon G, VonKorff M. Medical comorbidity and validity of DSM-IV depression criteria. 2006;36:2736.

42. Sanz E, De-las-Cuevas C, Kiuru A, Bate A, Edwards R. Selective serotonin reuptake inhibitors in pregnant women and neonatal withdrawal syndrome: a database analysis. Lancet 2005;365:482-7. [PubMed: 15705457]

43. McElroy S, Kotwal R, Malhotra S, Nelson E, Keck P, Nemeroff C. Are mood disorders and obesity related? A review for the mental health professional. J Clin Psychiatry 2004;65:634-51. [PubMed: 15163249]

44. Faith M, Matz P, Jorge M. Obesity-depression associations in the population. J Psychosom Res 2002;53:935-42. [PubMed: 12377306]

45. Stunkard A, Fernstrom M, Price A, Frank E, Kupfer D. Direction of weight gain in recurrent depression: Consistency across episodes. Arch Gen Psychiatry 1990;47:857-60. [PubMed: 2393344]

46. Carter F, Bulik C, Joyce P. Direction of weight change in depression. J Affect Disord 1994;30:5760. [PubMed: 8151050]

47. Cassidy K, Kotynia-English R, Acres J, Flicker L, Lautenshlager N, Almeida O. Association between lifestyle factors and mental health measures among community-dwelling older women. Aust NZ J Psychiatry 2004;38:940-7.

48. Sherwood N, Jeffery R, Wing R. Binge status as a predictor of weight loss treatment outcome. Int J Obes Relat Metab Disord 1999;23:485-93. [PubMed: 10375051]

49. French S, Jeffery R, Sherwood NN-SD. Prevalence and correlates of binge eating in a nonclinical sample of women enrolled in a weight gain prevention program. Int J Obes Relat Metab Disord 1999;23:576-85. [PubMed: 10411230]

50. Musante G, Costanzo P, Friedman K. The comorbidity of depression and eating dysregulation processes in a diet-seeking obese population: a matter of gender specificity. Int J Eat Disord 1998;23:65-75. [PubMed: 9429920]

51. Linde J, Jeffery R, Levy R, et al. Binge eating disorder, weight control self-efficacy, and deprssion in overweight men and women. Int J Obes Relat Metab Disord 2004;28:418-25. [PubMed: 14724662]

52. Schwartz T, Nihalani N, Jindal S, Virk S, Jones N. Psychiatric medication-induced obesity: a review. Obes Rev 2004;5:115-21. [PubMed: 15086865]

53. Myers A, Rosen J. Obesity stigmatization and coping: relation to mental health symptoms, body image, and self-esteem. Int J Obes Relat Metab Disord 1999;23:221-30. [PubMed: 10193866]

54. Pereira M, Kartashov A, Ebbeling C, et al. Fast-food habits, weight gain, and insulin resistance (the CARDIA study): 15-year prospective analysis. Lancet 2005;365:36-42. [PubMed: 15639678]

55. Vandegrift D, Yoked T. Obesity rates, income, and suburban sprawl: an analysis of US states. Health Place 2004;10:221-9. [PubMed: 15177197]

56. Block J, Scribner R, DeSalvo K. Fast food, race/ethnicity, and income: a geographic analysis. Am J Prev Med 2004;27:211-7. [PubMed: 15450633]

57. Puhl R, Brownell K. Psychosocial origins of obesity stigma: toward changing a powerful and pervasive bias. Obes Rev 2003;4:213-27. [PubMed: 14649372]

58. Gustafson T, Sarwer D. Childhood sexual abuse and obesity. Obes Rev 2004;5:129-35. [PubMed: 15245381]

59. Oquendo M, Barrera A, Ellis S, et al. Instability of symptoms in recurrent major depression: a prosepective study. Am J Psychiatry 2004;161:255-61. [PubMed: 14754774] 


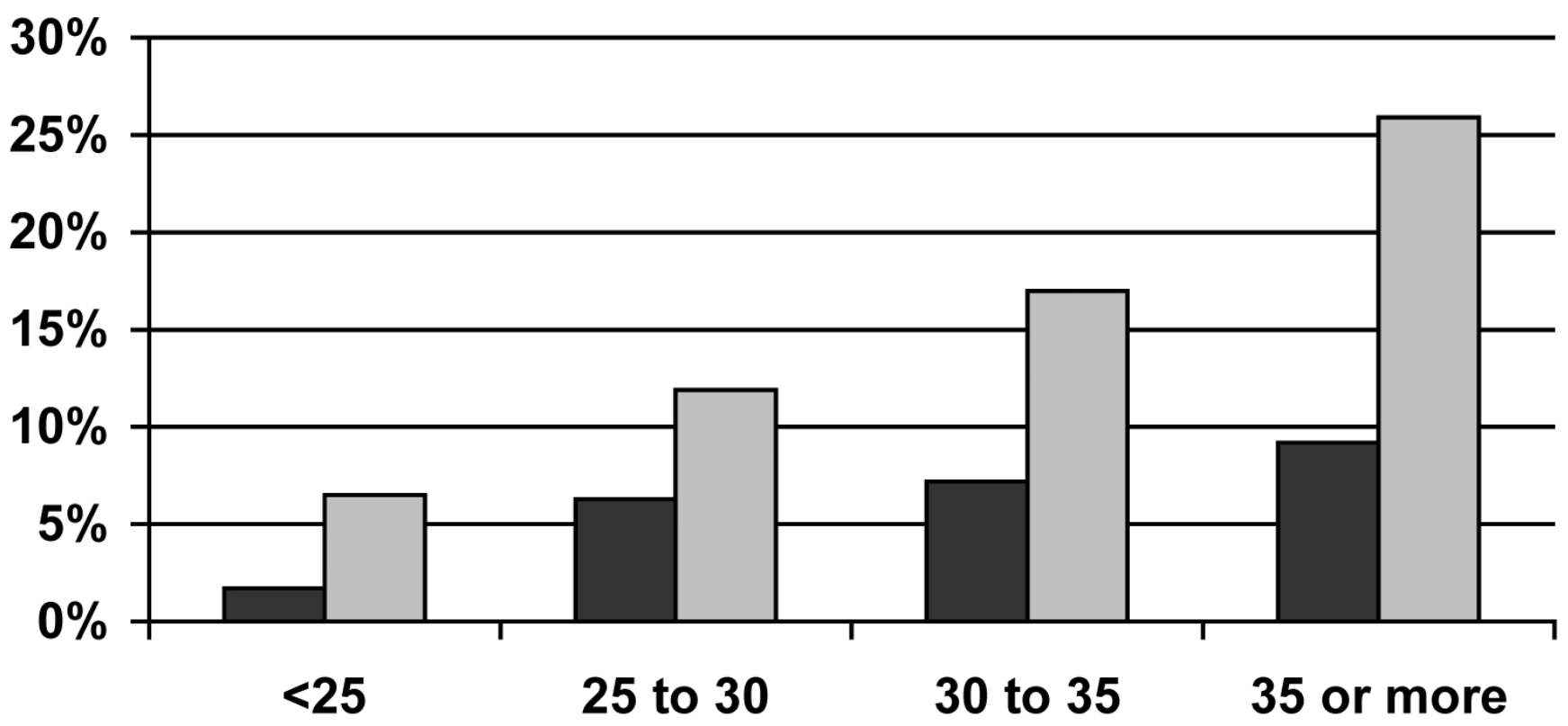

\section{Major Depression $\square$ PHQ Score $>=10$}

Figure 1.

Prevalence of current depression according to Body Mass Index 


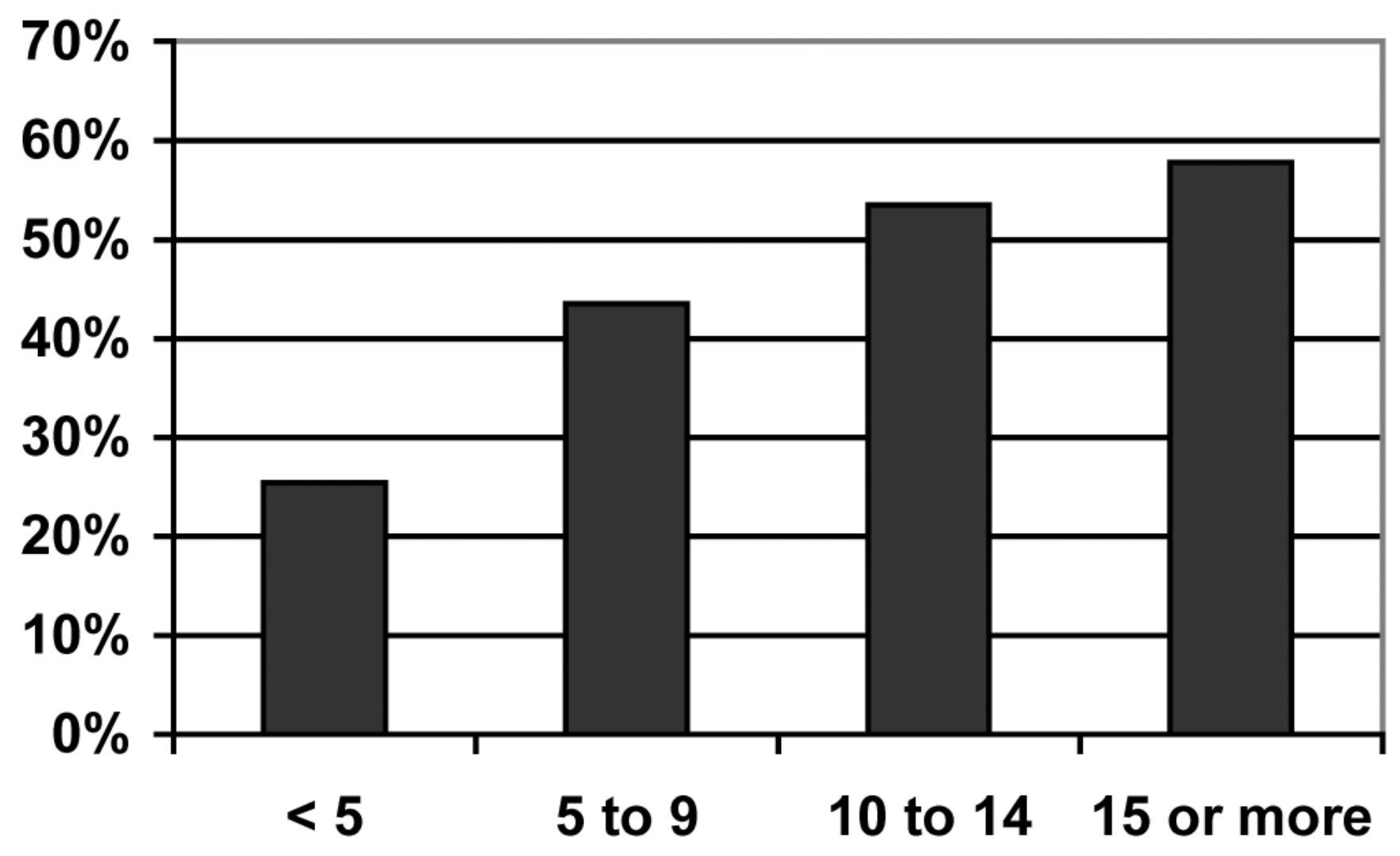

Figure 2.

Prevalence of obesity (BMI $\geq 30$ ) according to PHQ depression score 
Table 1

Demographic and clinical characteristics of survey respondents according to obesity and depression status. Sample size numbers reflect actual number of respondents; all other results incorporate sampling weights.

\begin{tabular}{|c|c|c|c|c|}
\hline & $\begin{array}{r}\mathrm{BMI}<30, \mathrm{PHQ}<10 \\
(\mathrm{n}=1263)\end{array}$ & $\begin{array}{r}\mathrm{BMI}<30, \mathrm{PHQ} \geq 10 \\
(\mathrm{n}=127)\end{array}$ & $\begin{array}{r}\mathrm{BMI} \geq 30, \mathrm{PHQ}<10 \\
(\mathrm{n}=2635)\end{array}$ & $\begin{array}{r}\mathrm{BMI} \geq 30, \mathrm{PHQ} \geq 10 \\
(\mathrm{n}=616)\end{array}$ \\
\hline Mean BMI & $24.1(24.0-24.3)$ & $25.1(24.4-25.7)$ & $36.2(35.9-36.6)$ & $37.9(36.9-38.9)$ \\
\hline Mean Age & $52.1(51.7-52.5)$ & $52.3(51.0-53.7)$ & $52.1(51.8-52.5)$ & $51.4(50.6-52.2)$ \\
\hline$\%$ White & $83.6(81.3-85.9)$ & $81.6(73.9-89.2)$ & $80.6(78.3-82.9)$ & $78.2(73.3-83.1)$ \\
\hline$\%$ African American & $5.0(3.6-6.3)$ & $5.6(1.2-10.1)$ & $11.2(9.3-13.1)$ & $9.3(6.4-12.2)$ \\
\hline$\%$ Other Race & $11.5(19.5-13.4)$ & $12.8(6.2-19.5)$ & $8.2(6.6-9.7)$ & $12.5(8.2-16.8)$ \\
\hline$\%$ Hispanic & $2.3(1.4-3.3)$ & $3.3(0.0-6.8)$ & $2.7(1.7-3.6)$ & $2.7(0.9-4.4)$ \\
\hline $\begin{array}{l}\% \text { Married/Living as } \\
\text { Married }\end{array}$ & $71.1(68.3-73.9)$ & $53.8(43.7-63.8)$ & $60.2(57.4-63.0)$ & $53.3(47.1-59.5)$ \\
\hline$\%$ College Graduate & $67.1(64.2-70.0)$ & $59.2(49.4-69.1)$ & 43.7 (40.9-46.6) & $34.0(28.2-39.8)$ \\
\hline$\%$ Current Smoker & $8.7(7.0-10.4)$ & $13.6(6.5-20.7)$ & $9.7(7.8-11.6)$ & $15.7(11.0-20.4)$ \\
\hline $\begin{array}{l}\% \text { Recent Antidepressant } \\
\text { Use }\end{array}$ & $17.0(14.6-19.4)$ & $31.7(22.1-41.4)$ & $24.6(22.2-27.1)$ & $50.8(44.5-57.0)$ \\
\hline $\begin{array}{l}\text { Mean Moderate Phys } \\
\text { Activity/Wk }\end{array}$ & $6.2(6.0-6.5)$ & $5.1(4.3-5.9)$ & $4.6(4.4-4.8)$ & $4.0(3.5-4.4)$ \\
\hline $\begin{array}{l}\text { Mean Vigorous Phys } \\
\text { Activity/Wk }\end{array}$ & $4.7(4.4-4.9)$ & $3.3(2.6-4.1)$ & $2.7(2.5-2.8)$ & $2.2(1.8-2.6)$ \\
\hline $\begin{array}{l}\text { Mean Est. Caloric Intake/ } \\
\text { Day }\end{array}$ & $1368(1342-1395)$ & $1340(1239-1440)$ & $1543(1515-1571)$ & $1831(1748-1914)$ \\
\hline $\begin{array}{l}\text { Mean Body } \\
\text { Dissatisfaction Score }\end{array}$ & $2.21(2.12-2.29)$ & $3.05(2.72-3.38)$ & $3.81(3.75-3.88)$ & $4.40(4.27-4.53)$ \\
\hline
\end{tabular}




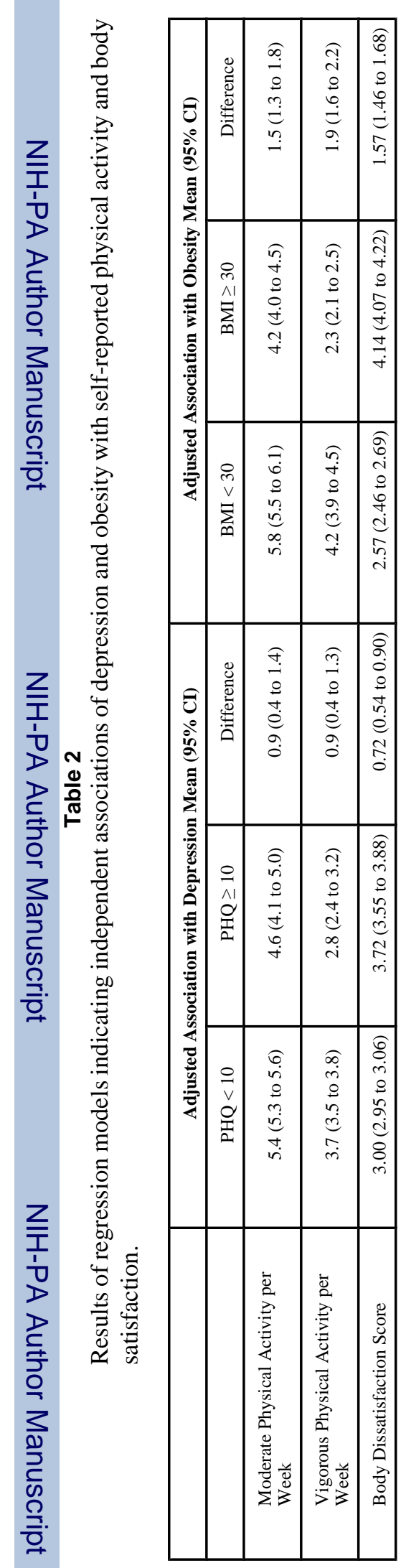

Gen Hosp Psychiatry. Author manuscript; available in PMC 2009 April 30. 